https://helda.helsinki.fi

\title{
Assessing branching structure for biomass and wood quality estimation using terrestrial laser scanning point clouds
}

\section{Pyorala, Jiri}

2018

Pyorala , J , Liang , X, Saarinen , N , Kankare , V , Wang , Y , Holopainen , M , Hyyppa , J \& Vastaranta, M 2018 , ' Assessing branching structure for biomass and wood quality estimation using terrestrial laser scanning point clouds ' , Canadian journal of remote sensing , vol. 44 , no. 5 , pp. 462-475 . https://doi.org/10.1080/07038992.2018.1557040

http://hdl.handle.net/10138/309291

https://doi.org/10.1080/07038992.2018.1557040

unspecified

acceptedVersion

Downloaded from Helda, University of Helsinki institutional repository.

This is an electronic reprint of the original article.

This reprint may differ from the original in pagination and typographic detail.

Please cite the original version. 
1 Assessing branching structure for biomass and wood quality estimation

2 using terrestrial laser scanning point clouds

3 Jiri Pyörälä ${ }^{1,2,3}$, Xinlian Liang ${ }^{2,3}$, Ninni Saarinen ${ }^{1,3}$, Ville Kankare ${ }^{1,3}$, Yunsheng Wang ${ }^{2,3}$, Markus $^{1,3}$

4 Holopainen ${ }^{1,3}$, Juha Hyyppä ${ }^{2,3}$, Mikko Vastaranta ${ }^{1,3,4}$

1 Department of Forest Sciences, University of Helsinki, Helsinki, FI-00014, Finland

2 Department of Remote Sensing and Photogrammetry, Finnish Geospatial Research Institute, Masala, FI-02431, Finland

3 Centre of Excellence in Laser Scanning Research, Finnish Geospatial Research Institute, Masala, FI-02431, Finland

4 School of Forest Sciences, University of Eastern Finland, Joensuu, FI-80101, Finland

*Correspondence: jiri.pyorala@helsinki.fi

Abstract

Terrestrial laser scanning (TLS) accompanied by quantitative tree-modeling algorithms can potentially acquire branching data non-destructively from a forest environment and aid the development and calibration of allometric crown biomass and wood quality equations for species and geographical regions with inadequate models. However, TLS's coverage in capturing individual branches still lacks evaluation. We acquired TLS data from 158 Scots pine (Pinus sylvestris L.) trees and investigated the performance of a quantitative branch detection and modeling approach for extracting key branching parameters, namely the number of branches, branch diameter $\left(b_{d}\right)$ and branch insertion angle $\left(b_{\alpha}\right)$ in various crown sections. We used manual point cloud measurements as references. The accuracy of quantitative branch detections decreased significantly above the live crown base height, principally due to the increasing scanner distance as opposed to occlusion effects caused by the foliage. $b_{d}$ was generally underestimated, when comparing to the manual reference, while $b_{\alpha}$ was estimated accurately: tree-specific biases were $0.89 \mathrm{~cm}$ and $1.98^{\circ}$, respectively. Our results indicate that full branching structure remains challenging to capture by TLS alone. Nevertheless, the retrievable branching parameters are potential inputs into allometric biomass and wood quality equations.

Keywords: Forestry, LiDAR, Modeling, Point clouds, Scots pine

\section{Introduction}

Size and shape of a tree crown and branches reflect how changes in climate or silviculture affect tree growth (Rubio-Cuadrado et al. 2018) and wood formation (Vanninen et al. 2000). Consequently, branching structures have implications on biomass accumulation (Helmisaari et al. 2002, Ogaya et al. 2007) and wood quality (Huuskonen et al. 2014, Kuprevicius et al. 2013, Mäkinen 1999). Tree 
biomass in particular is one of the most influential attributes required in terrestrial carbon cycle models. Terrestrial carbon in the forest is usually estimated by multiplying forest biomass by a carbon content factor (Penman et al. 2003). Wood quality estimations are considered essential to accurately target harvesting operations and to optimize wood procurement for more sustainable forest resource usage.

Allometric equations that utilize forest inventory attributes (e.g., species, diameter-at-breast height $(D B H)$, and tree height $(H))$ are available for biomass components such as the stem and crown (Jenkins et al. 2003, Liepiņš et al. 2018, Picard et al. 2012, Repola 2009, Zianis et al. 2005). However, data with which to build the models are only available for a limited number of tree species and geographical regions, and they often lack explanatory variables related to crown size and structure, which makes them poorly transferrable across regions (Duncanson et al. 2015, Temesgen et al. 2015). The wood quality of standing timber can additionally be determined using branching parameters (Benjamin et al. 2007, Lyhykäinen et al. 2009, Uusitalo 1997). Branches have a direct, mechanical influence on wood quality in sawn timber, because they distort the stem wood grain orientation and decrease wood stiffness and strength (Samson 2007). Branch knots are often the main defect measured in the visual grading of sawn goods (STMY 2016). Potential variables to more accurately explain crown biomass and wood quality may thus include geometric features of the crown and branches (e.g. crown length, width, and volume, number of branches, variation in branch size, whorlto-whorl distances, height of the lowest dead branch $\left(H_{d b}\right)$, and height of the live crown base $\left.\left(H_{l c}\right)\right)$.

Acquiring detailed data on branching structure for crown biomass and wood quality studies is notoriously difficult. Destructive measurements are required for developing new models or equations for species and geographical areas without existing models, and for calibrating existing models. These measurements are laborious, time consuming, and often not feasible in locations such as permanent sample plots or in urban or conservation areas. Terrestrial laser scanning (TLS) provides a threedimensional (3D) point-based representation of forest canopies and can be used to characterize both tree- and plot-level structural information through the analysis of spatial point distribution or gap probability, or by modeling individual trees using geometrical primitives (Jupp et al. 2007, Liang et al. 2016, Newnham et al. 2015). The latter approaches have gained increasing interest in the literature, as they have been shown to hold potential for representing the scanned tree structures with the most detail, including a geometrical presentation of individual branches and twigs (Bournez et al. 2017). Most geometrical tree-modeling approaches can be roughly broken down into three main steps (Bucksch et al. 2008, Côté et al. 2011, Gorte et al. 2004, Liang et al. 2012, Pfeifer et al. 2004, Pyörälä et al. 2018b, Raumonen et al. 2013, Xia et al. 2015, Zhong et al. 2017): First, the context of points is characterized, and those belonging to the stems and branches are identified by applying point classification techniques. Second, the points identified as woody components are segmented and organized into a hierarchical structure resembling the tree phenology, based on point connectivity or 
pattern recognition analyses. Third, the stems, branches, and twigs are modeled by fitting geometrical primitives, most often circles or cylinders, to the points.

Studies applying TLS point clouds to estimate the biomass of woody tree crown components have so far concurred that crown-related biomass components can be more accurately estimated using TLS point cloud features than with existing allometric models (Calders et al. 2015, Hackenberg et al. 2015, Hauglin et al. 2013, Kankare et al. 2013, Stovall et al. 2018, Temesgen et al. 2016). Consequently, studies are increasingly using TLS data to infer the stem and branch biomass directly from the geometrical tree models, although how the methodologies perform across various vertical stem sections with varying branch properties remains unclear. The omission of structures along the length of tree stems has a crucial effect on the performance of geometrical tree-modeling methods in the extraction of branching structures and, consequently, their applicability into acquiring input for biomass and wood quality equations (Pyörälä et al. 2018b).

In this study, we analyzed the performance of a geometrical tree-modeling method (Pyörälä et al. $2018 \mathrm{~b}$ ) in the detection and modeling of individual branch bases across a range of vertical locations and crown conditions. Our objectives were to explicitly quantify the various factors that affected the parameter extraction, and to analyze the implications of our results for the use of geometrical TLS tree models in the development and calibration of biomass and wood quality models.

\section{Materials}

The data consisted of 158 Scot pines from six two-hectare forest stands. The stands were located in southern Finland, with four stands in Evo $\left(61.19^{\circ} \mathrm{N}, 25.11^{\circ} \mathrm{E}\right)$ and two in Orimattila $\left(60.80^{\circ} \mathrm{N}, \mathrm{E}\right.$ $25.73^{\circ} \mathrm{E}$ ). Based on stand-wise forest inventory data from 2013, the tree species composition varied from nearly pure Scots pine forests to mixed Scots pine and Norway spruce (Picea abies H. Karst) forests (Table 1). The sample trees were located in groups of three to six trees and were evenly distributed around each stand. From each sample tree, $D B H$ was measured with calipers on two perpendicular planes. A Vertex III hypsometer (Haglöf, Sweden) was used to determine $H, H_{l c}$, and $H_{d b} . H$ was the height from the ground to the tree top, $H_{l c}$ the height from the ground to the lowest living branch that was separated from the live crown by a maximum of two dead whorls, and $H_{d b}$ the height from the ground to the lowest dead branch that was approximately over $15 \mathrm{~mm}$ in diameter. All Vertex measurements averaged three repetitions. Table 2 shows descriptive statistics of the sample trees at each stand, as measured in the field in August 2014.

TLS data were collected using a Faro Focus ${ }^{3 \mathrm{D}}$ X 330 phase-shift scanner (Faro Technologies Inc., FL, USA) during August and September 2014. Each tree group was scanned from 5-10 locations to ensure that each tree was recorded from all sides, resulting in 197 scans. The mean horizontal scanner-to-tree distance at breast height was $9.8 \mathrm{~m}$ (Table 1). With the scanner settings used, point-to- 
point sampling distance was $6.3 \mathrm{~mm}$ at a 10 -meter distance. Six spherical targets were used within each of the five tree groups to allow co-registration of the point clouds into a single combined point cloud using Faro Scene 5.2.1 software. Table 1 shows the registration errors given by the software.

\section{Methods}

\section{Data sampling and manual measurements}

As manually identifying and measuring each individual branch from all sample trees is impractical, we used a sampling scheme to divide each sample tree into stem section strata using $H_{d b}, H_{l c}$, and $H$ derived from the field measurements. Dead crown (between $\mathrm{H}_{\mathrm{db}}$ and $\mathrm{H}_{\mathrm{lc}}$ ) and live crown (between $\mathrm{H}_{\mathrm{lc}}$ and $\mathrm{H}$ ) were divided into two strata of equal length (upper half and lower half). In other words, we measured five vertical stem sections: the stem below $H_{d b}$, the lower half of the dead crown, the upper half of the dead crown, the lower half of the live crown, and the upper half of the live crown (Figure 1a).

We manually extracted the point clouds of individual sample trees from the merged point clouds. For every tree, a sample height was randomly selected from each of the five stem sections. All visually identifiable first-order branch bases (i.e. the branch bases diverting from the stem) $0-50 \mathrm{~cm}$ below and above (i.e. $1 \mathrm{~m}$ in total) the selected height were included in the sample. We extracted points belonging to each visually identified branch base and defined a tight circle that encompassed the extracted points perpendicular to the longitudinal axis of the identified branch. Three geometrical branch attributes were measured as illustrated in Figure 1c: branch diameter $\left(b_{d}\right)$, branch height $\left(b_{h}\right)$, and branch insertion angle $\left(b_{\alpha}\right) . b_{d}$ was the diameter of the manually fitted circle, $b_{h}$ the difference between the circle center $\left(b_{c}\right)$ z-coordinate and the visually estimated root collar height, and $b_{\alpha}$ was the angle between a vertical Z-axis $n_{z}=[0,0,1]$ and the normal $e_{0}=\left[\mathrm{e}_{1}, \mathrm{e}_{2}, \mathrm{e}_{3}\right]$ of the fitted circle, similarly to the literature (Samson 1993).

\section{The quantitative branch detection and modeling -method}

We produced geometrical tree models for each tree that described the tree stems and the first-order branching structure along the full range that was visible in the point clouds. The tree stems were modeled following the approaches of Liang et al. (2012). Points associated with tree stems were identified using principal component analysis (PCA), to estimate the direction vector in which the points exhibit most variance. We assumed that points exhibiting most variance along a near-vertical direction originated from the tree stems. Cylinders were then fitted to the stem points using a weighted least-squares optimization to minimize the distance of the points to the cylinder surface. After stem modeling, points within a horizontal distance of $50 \mathrm{~cm}$ from the modeled stem surface were selected and divided into $15-\mathrm{cm}$ segments, with adjacent segments overlapping by $10 \mathrm{~cm}$. Points around the stem model in each segment were analyzed using distributions of point density and the 
mean distance of the points as per 360 degrees around the stem model (Figure 1b). Two point distributions were used to separate branch points from noisy points, e.g. from branch bumps or other stem deformations that should not have a peak in the distribution of mean distance. The distributions were smoothed by a convolution with a Gaussian window function by means of the Fast Fourier Transform (Cooley et al. 1965). The Continuous Wavelet Transform (CWT) function (Du et al. 2006), an iterative pattern-matching algorithm, was utilized in identifying the peaks in the smoothed distributions. Positions exhibiting peaks from 5 to $45^{\circ}$ in width for the point density function and from 20 to $75^{\circ}$ in width for the mean distance function were defined as branch positions. Points falling within each peak were labeled as belonging to a single branch. Branch points were then projected onto a horizontal plane perpendicular to the longitudinal axis of the branch and modeled as a circle using the Random sample consensus (RANSAC) algorithm (Fischler et al. 1981). Circle diameter was considered to represent $b_{d}$, and $b_{\alpha}$ was solved from the longitudinal axis direction of the points given by PCA. Branches with $b_{d}$ less than $7 \mathrm{~mm}$ and more than $100 \mathrm{~mm}$, and with $b_{\alpha}$ less than $20^{\circ}$ and more than $120^{\circ}$ were filtered out, as they were assumed to be false positives resulting from noise or stem deformations. The method pipeline is illustrated in Figure 1 and described in more detail in Pyörälä et al. (2018b).

\section{Evaluation of the quantitative method}

For evaluation of the quantitative method, we selected a sample of the quantitatively detected branches using same sample heights as for the manual references. The sample of quantitatively detected branches was compared to the reference branches using all samples from each tree (one sample includes branches along one 1-m section of stem from a given stratum, i.e., five samples from each tree), and the samples in each stem section strata separately (i.e., one sample from each tree). The number of branches detected by the quantitative method $\left(n_{q}\right)$ and the number of branches identified visually $\left(n_{m}\right)$ were calculated separately for each sample. Then, for each sample, we calculated the difference between $n_{q}$ and $n_{m}$. The number of false positives or commission errors $\left(n_{c}\right)$ and false negatives or omission errors $\left(n_{o}\right)$ made by the quantitative method were assessed such that a negative value was considered to indicate branches being omitted, and a positive value to indicate branches being falsely detected (commission error). The accuracy of quantitative branch detection was defined for the stem section strata as well as for entire trees (i.e., combining all samples from a tree) as in Equation 1.

$$
\operatorname{Accuracy}(\%)=\frac{n_{q}}{n_{q}+\left|n_{o}\right|+n_{c}} * 100
$$

Estimates for $b_{d}$ and $b_{\alpha}$ derived from the RANSAC-circle-fitting method and PCA, respectively, were compared to the manual measurements. Accuracies of the $b_{d}$ and $b_{\alpha}$ estimates were evaluated by comparing the minimum, mean, and maximum branch parameter values between the manual 
references and the quantitative data in each sample. We reported the root-mean-squared error (RMSE) and the simple regression model $\mathrm{R}^{2}$ between the data sets separately in each stratum and when considering all samples. $b_{\alpha}$ accuracy is likely to affect $b_{d}$ accuracy, as it determines the axis used to project the points onto a horizontal plane for circle fitting. Therefore, we also inspected whether the sample-specific mean estimation error in $b_{d}$ and $b_{\alpha}$ had an impact on the other parameter's estimation errors.

Previous research has reported that the quality and completeness of the point cloud is highly dependent on scanner distance and occlusion (Abegg et al. 2017, Pyörälä et al. 2018b). Here, we examined to what degree scanner distance and self-occlusion affected branch detection. The height above $H_{l c}$ was considered to represent the magnitude of foliage occlusion, because the quantity of foliage borne by the live crown, and thus the occlusion, was expected to increase cumulatively above $H_{l c}$ (Figure 2). Below $H_{l c}$, the dead crown was supposed to bear no foliage and to cause no occlusion. We evaluated the quantitative branch detection accuracy within the live crown strata in relation to the $3 \mathrm{D}$ scanner distance and height above $H_{l c}$ using a multiple linear regression model. We reported the model $\mathrm{R}^{2}$ and inspected the magnitude of the parameter estimate values for either explanatory variable: the parameter estimate value (or slope) gave the rate at which the detection accuracy was estimated to decline when the scanner distance or height above $H_{l c}$ increased by $1 \mathrm{~m}$. In addition, to analyze the statistical significance of the relationships, we reported the standard error (SE), t-statistic and $p$-value of the parameters based on the Student's t-test.

We expected the quantitative branch detection method to be sensitive to branch size. A simple regression model was used to define the impact of sample-specific mean $b_{d}$ to quantitative branch detection accuracy in each stem section strata and when considering all samples from a tree. We reported parameter estimates, $\mathrm{SE}$, t-statistic, and $p$-value.

\section{Results}

Compared to our manual measurements, the quantitative branch detection method had an overall accuracy of $68.6 \%$, and was at its highest (81.0-82.6\%) in the dead parts of the crown (Figure 3 ). The number of manually detectable branches increased with height in the dead crown, but decreased significantly above $H_{l c}$ (Table 3, Figure 3). The proportions of omission and commission errors to the number of manually detected branches were $34.4 \%$ and $3.0 \%$, respectively. The method made 30 commission errors in the stem section stratum below $H_{d b}$. Based on visual inspections, the false positives were due to noisy points, loose bark, stem deformations, and in one case a broken branch that was detected twice by the quantitative method. In addition to causing commission errors, similar factors were also found to cause some of the omission errors of branches that intuitively should be detectable, if not for the aforementioned factors that introduced noise to the point distribution and caused the CWT peak detection to fail (Figure 4). 
Mean and maximum $b_{d}$ were larger in the live than in the dead crown, while mean $b_{a}$ was lower in the live than in the dead crown (Table 3 ). In all, sample-specific mean $b_{d}$ were estimated with an RMSE of $0.94 \mathrm{~cm}$ (bias $-0.89 \mathrm{~cm}$ ), and mean $b_{\alpha}$ with a $7.76^{\circ} \mathrm{RMSE}$ and $1.98^{\circ}$ bias (Figure 5). Estimate errors of $b_{d}$ and $b_{\alpha}$ were independent of the magnitude of the estimated parameter, and of the error in the other parameter (Figure 6).

The correlation coefficient $(r)$ between scanner distance and height above $H_{l c}$ was 0.27 . Based on the multiple regression analysis, scanner distance was the main factor contributing to the diminishing branch detection accuracy in the live crown (Table 4). Model RMSE and $\mathrm{R}^{2}$ were 0.26 and 0.35 , respectively. The number of detected branches decreased gradually in both data sets as the distance from the scanner increased, while the occlusion effect was notable only in the reference data (Figure 7).

Lastly, the simple regression analysis showed that the effect of sample-specific, manually measured mean $b_{d}$ to branch detection accuracy was not statistically significant, except in the lower half of the dead crown (Table 5).

\section{Discussion}

We analyzed the performance of a geometrical tree-modeling method in quantitative branch detection, and examined the capacity of TLS to provide input data for calibration of crown biomass and wood quality equations across different parts of the stem. The method used in our study represented an example of the geometrical tree-modeling methods that have gained increasing attention in recent forestry-related TLS approaches. However, the methods still largely lack evaluation of their accuracy in branch structure extraction with respect to limiting factors such as the decreasing point cloud quality in tree crowns. Results in our current study entailed a comparison of the automated parameter extraction to manual point cloud measurement data acquired using a sampling procedure from the original TLS point cloud. The sampling approach may have introduced biases and accurately represented the actual number of branches only in the dead parts of the crown closer to the stem base. A diminishing number of manually detectable branches was observable for the sample higher up the live crown (Table 3, Figure 3). Figure 7 suggested that the completeness of the manual reference data above $H_{l c}$ was affected partly by both increasing scanner distance and increasing occlusion effect (Figure 2). The estimated reference branch parameters behaved as expected based on the literature: $b_{d}$ increased over the dead crown (Table 3) (Maguire et al. 1999, Mäkinen et al. 1998), and $b_{\alpha}$ decreased with branch height (Table 3) (Mäkinen et al. 1998, Osborne et al. 2015).

237 The quantitative branch detection accuracy compared to manual measurements (64.8\%) was lower in our current study than in Pyörälä et al. (2018b) (69.9\%), where only the log-section (stem diameter > $15 \mathrm{~cm}$ ) and largest branches in each whorl were considered. The results implied that the lower parts of 
the tree were better covered by TLS and larger branches were more easily detected. Here, the first assumption was supported by the fact that the quantitative branch detection accuracy and the number of reference branches decreased rapidly above $H_{l c}$ in our data (Figure 3). This effect has been noted in previous research (Boudon et al. 2014, Eysn et al. 2013) and, in this work, we aimed to quantify the factors contributing to the effect. When we analyzed the interaction between the distance from the scanner and the occlusion effect caused by the tree crown above $H_{l c}$ (Figure 2, Figure 7), the scanner distance affected the branch detection accuracy to such a degree that the occlusion effect was not significantly present in the data (Table 4). In addition, the viewing angle between the scanner and the measured point has an additional effect on the magnitude of self-occlusion, which was not considered. The second assumption was not supported by our data, as in this study mean branch size did not have a statistically significant effect on branch detection accuracy in most parts of the tree (Table 5), except for the lower part of the dead crown, where mean $b_{d}$ was at its lowest (Table 3$)$. In general, it is worth noting that there was relatively little variance among $b_{d}$ in the data (Table 3 ).

Stand structure and scanning setup affect the uniformity of point cloud density and the magnitude of occlusion. The theoretical probability of a laser beam hitting an object largely depended on object size, the scanner angular resolution, and the evenness of the scanning location distribution, which can be used to minimize the distance from the scanner to each tree and avoid occlusion (Abegg et al. 2017). Wilkes et al. (2017) proposed that to capture upper canopy structures, the scanning locations should be sampled using a 10-by-10-m grid. In compliance with the results of our current study, we also argue that to capture branches above $H_{l c}$, paying attention to scanner-to-tree distances and covering all sides of a tree is crucial. On the other hand, shortening scanner-to-tree distances may restrict the spatial coverage. The multi-scan setup used in our study ensured complete stems were scanned, and had an average distance of $9.8 \mathrm{~m}$ between a tree and a scanner. It could be beneficial to implement scanner settings that result in a smaller point-to-point sampling distance than in our study (6.3 $\mathrm{mm}$ at a $10-\mathrm{m}$ distance), to avoid compromising the size of the area covered. Further improvements in data acquisition technology could include use of pulse-based laser scanners, or scanners that record multiple returns or the full waveform. Nevertheless, diminishing point density will always occur higher in the tree with any TLS scanning setup or technique. If more commonly available in the future, in- or above-canopy measurements using laser scanners mounted on unmanned aerial vehicles could enable better coverage of upper parts of the tree crowns from closer distance and thus with higher point density (Jaakkola et al. 2017, Wallace et al. 2012).

The chosen branch detection and modeling methods may also affect the expected completeness and accuracy of a retrieved branching structure. In manual inspections, the existence of a branch can visually be interpreted even from a sparse point cloud using multiple viewing angles to distinguish a branch-like shape from the surrounding points. The automated method used in our study was based on pattern matching (Figure 1b). Noise, stem deformations, and underestimated stem diameters may 
result in branches being omitted even if they are visible in the point cloud, as illustrated in Figure 4, due to the threshold values regarding the smoothing convolution with a Gaussian window function, allowed peak width in CWT, and the maximum $b_{\alpha}$. These particular omission errors could partly be avoided if the information of tree trunk points as defined in the stem-modeling phase (Liang et al. 2012) was used to exclude these points from the branch detection phase. We will implement this last improvement in future applications of the method.

Most TLS point cloud based geometric tree-modeling methods found in the literature base the branch detection on point connectivity analyses in the point neighborhood, which is a different approach than in our present study (Bucksch et al. 2008, Gorte et al. 2004, Raumonen et al. 2013). For example, the results in Boudon et al. (2014) and Bournez et al. (2017) implied that connectivity analyses also face challenges higher in the tree crown given the decreasing completeness of the point cloud. One possible solution to substitute for omitted branches could be an approach that combined quantitative point cloud processing with a process-based tree growth model to overcome the data gaps in the point cloud (Côté et al. 2011, Côté et al. 2012). However, such an approach requires existing equations suited for particular species and geographical regions. One of the motivations in developing TLS point cloud -based tree-modeling methods is to enable data collection for the development of new equations as well as for the calibration of existing allometric models, be they process-based or empirical. In such case, data gaps cannot be overcome by modeling.

Our results showed that $b_{d}$ was generally underestimated by the quantitative method compared to the manual method (Figure 5). The effect of the measurer plays a role in manual circle-fitting. A circle can be fitted to the projection of branch points in various ways. In this study, the fitting aimed to exclude noise and the elliptical shape of a branch bottom (Figure 1c), in contrast to our previous study Pyörälä et al. (2018b), where the manual measurements did not account for noise or elliptical shape, but the circle-fitting utilized all points that appeared to belong to a branch. We changed the measurement principle in this study, because we considered the current approach to more realistically represent the size of the branch. Despite the different measurement principles between the two studies as described, the quantitative method underestimated $b_{d}$ in both Pyörälä et al. (2018b) (whorl-specific maximum branch diameters underestimated on average by $-0.34 \mathrm{~cm}$ ), and the current study (treespecific mean branch diameters underestimated on average by $-0.89 \mathrm{~cm}$ ) (Figure 5, Figure 6).

The $b_{\alpha}$ estimates from PCA did not differ statistically from the manual measurements when treespecific mean and maximum values were compared (Figure 5). As PCA is used to distinguish the direction in which the points exhibit most variation, the results indicated that the longitudinal axis of the branch was more completely recorded than the horizontal axis. Figure 4 showed that the insertion angle estimation errors are mostly unbiased in respect to the magnitude of the manually measured $b_{\alpha}$. The sharp trend in the maximum error values for $b_{\alpha}$ resulted from the maximum value threshold that 
was set at $120^{\circ}$ to filter out likely false positives. In addition, the errors in $b_{\alpha}$ estimates did not have a clear effect on $b_{d}$ estimate accuracy (Figure $6 \mathrm{c}$ ), although a slight trend was observable.

Previous studies on the accuracy of individual branch modeling are sparse. Dassot et al. (2012) excluded branches below $7 \mathrm{~cm}$ in diameter, but reported $\pm 30 \%$ differences between tree-specific branch volume estimates and destructive measurements. Côté et al. (2013) combined quantitative point cloud processing to process-based tree growth modeling and compared the results to destructive measurements from six trees. The group reported relative RMSEs of $20 \%$ and $25 \%$ for $b_{d}$ and $b_{\alpha}$, respectively. Hackenberg et al. (2015) reported that compared to destructive biomass measurements, branch modeling by means of cylinder-fitting was more accurate for branches with diameters above 7 cm. Lau et al. (2018) also reported accurate results in $b_{d}$ estimation, but excluded branches below 10 $\mathrm{cm}$ in diameter. Based on our results and the literature, individual branches remain challenging to retrieve accurately from TLS point clouds, especially for coniferous species where most branches are small in diameter.

Our results and previous research implied that unbiased crown biomass estimates in a forest environment are probably not achievable directly from branch-to-branch measurements using TLS point clouds. Instead, select branching features that are extractable from TLS point clouds could be used as additional explanatory variables in allometric biomass models to account for local variation in crown structure (Kankare et al. 2013, Stovall et al. 2018, Temesgen et al. 2016). On the other hand, based on the current results and our previous studies, it is apparently possible to derive branching parameters from TLS point clouds that are applicable to wood quality estimations (Kankare et al. 2014, Pyörälä et al. 2018a, Pyörälä et al. 2018b). For example, $H_{d b}$ is one of the most commonly used variable in estimating wood quality in standing timber, because it can be used to estimate the yield of the branchless bottom logs, the most valuable log product (Lyhykäinen et al. 2009, Uusitalo 1997). Our current study had false positive branch detections below $H_{d b}$, which could lead to underestimating the bottom log yield. Furthermore, a comparison to X-ray scanning data of logs in Pyörälä et al. (2018a) revealed a dependency between the maximum interior knot diameter within a log measured from X-ray scanning images and the maximum $b_{d}$ measured manually from the TLS point cloud. In Pyörälä et al. (2018b) and in our current study, the quantitative method underestimated $b_{d}$, which may mean that the maximum knot size within a tree was also underestimated.

\section{Conclusion}

Tree crown and branching parameters are closely related to tree growth and wood formation. Due to the difficulty in measuring these metrics directly by conventional, destructive means, a wide field of applications relies on established relationships between crown biomass, wood quality, and more readily measurable tree characteristics such as $D B H, H$, and $H_{d b}$. However, laborious local reference measurements are required to build such equations for new species and regions. Furthermore, in the 
case of biomass modeling, the accuracy of allometric models is lower at predicting the biomass of the crown components than of the stem. Using TLS point cloud -based geometrical tree-modeling approaches to measure variables describing the branching structure could reduce the need for destructive measurements and improve the accuracy of the equations in estimating the crown biomass and the expected wood quality, even if full branching structures are not captured. The initial equation development would also require species-specific destructive measurements of tree biomass, but the extractable branching parameters describe tree-specific differences in growth and wood formation across various regions in more detail than the currently applied equations.

\section{Acknowledgements}

Our work was supported by the financial aid received from the Finnish Academy project "Centre of Excellence in Laser Scanning Research (CoE-LaSR) [272195]", Ministry of Agriculture and Forestry of Finland project "Puuston laatutunnukset" [OH300-S42100-03], Foundation for Research of Natural Resources in Finland [1780/15, 1790/16 and 1798/17], Finnish Forest Foundation [2014092904], and Jenny ja Antti Wihurin rahasto - foundation. The authors acknowledge Evo Forest School for providing the forest plots and their facilities for our use. Professor Jori Uusitalo, Olli Ylhäisi and Pekka Helminen from Natural Resources Institute Finland are acknowledged for collecting and providing the conventional field data. Professor Nicholas Coops from the Faculty of Forestry at University of British Columbia is acknowledged for providing scientific advice. Stella Thompson edited the language.

\section{References}

Abegg, M., Kükenbrink, D., Zell, J., Schaepman, M. E., and Morsdorf, F. 2017. "Terrestrial Laser Scanning for Forest Inventories-Tree Diameter Distribution and Scanner Location Impact on Occlusion." Forests, Vol. 8 (No. 6): pp. 184.

Benjamin, J., Chui, Y., and Zhang, S. 2007. "A Method to Assess Lumber Grade Recovery Improvement Potential for Black Spruce Logs Based on Branchiness." Forest Products Journal, Vol. 57 (No. 12): pp. 34.

Boudon, F., Preuksakarn, C., Ferraro, P., Diener, J., Nacry, P., Nikinmaa, E., and Godin, C. 2014. "Quantitative Assessment of Automatic Reconstructions of Branching Systems Obtained from Laser Scanning." Annals of Botany, Vol. 114 (No. 4): pp. 853-862.

Bournez, E., Landes, T., Saudreau, M., Kastendeuch, P., and Najjar, G. 2017. "From Tls Point Clouds to 3d Models of Trees: A Comparison of Existing Algorithms for 3d Tree Reconstruction." ISPRS-International Archives of the Photogrammetry, Remote Sensing and Spatial Information Sciences, Vol. 42 (No. 2): pp. 113-120.

Bucksch, A., and Lindenbergh, R. 2008. "Campino-a Skeletonization Method for Point Cloud Processing." ISPRS Journal of Photogrammetry and Remote Sensing, Vol. 63 (No. 1): pp. 115127.

Calders, K., Newnham, G., Burt, A., Murphy, S., Raumonen, P., Herold, M., Culvenor, D., Avitabile, V., Disney, M., and Armston, J. 2015. "Nondestructive Estimates of above-Ground Biomass Using Terrestrial Laser Scanning." Methods in Ecology and Evolution, Vol. 6 (No. 2): pp. 198208. 
Cooley, J. W., and Tukey, J. W. 1965. "An Algorithm for the Machine Calculation of Complex Fourier Series." Mathematics of Computation, Vol. 19 (No. 90): pp. 297-301.

Côté, J.-F., Fournier, R. A., and Egli, R. 2011. "An Architectural Model of Trees to Estimate Forest Structural Attributes Using Terrestrial Lidar." Environmental Modelling \& Software, Vol. 26 (No. 6): pp. 761-777.

Côté, J.-F., Fournier, R. A., Frazer, G. W., and Niemann, K. O. 2012. "A Fine-Scale Architectural Model of Trees to Enhance Lidar-Derived Measurements of Forest Canopy Structure." Agricultural and Forest Meteorology, Vol. 166 (No. 1): pp. 72-85.

Côté, J.-F., Fournier, R. A., and Luther, J. E. 2013. "Validation of L-Architect Model for Balsam Fir and Black Spruce Trees with Structural Measurements." Canadian Journal of Remote Sensing, Vol. 39 (No. s1): pp. S41-S59.

Dassot, M., Colin, A., Santenoise, P., Fournier, M., and Constant, T. 2012. "Terrestrial Laser Scanning for Measuring the Solid Wood Volume, Including Branches, of Adult Standing Trees in the Forest Environment." Computers and Electronics in Agriculture, Vol. 89 (No.: pp. 86-93.

Du, P., Kibbe, W. A., and Lin, S. M. 2006. "Improved Peak Detection in Mass Spectrum by Incorporating Continuous Wavelet Transform-Based Pattern Matching." Bioinformatics, Vol. 22 (No. 17): pp. 2059-65. doi: 10.1093/bioinformatics/btl355.

Duncanson, L. I., Dubayah, R. O., and Enquist, B. J. 2015. "Assessing the General Patterns of Forest Structure: Quantifying Tree and Forest Allometric Scaling Relationships in the United States." Global Ecology and Biogeography, Vol. 24 (No. 12): pp. 1465-1475.

Eysn, L., Pfeifer, N., Ressl, C., Hollaus, M., Grafl, A., and Morsdorf, F. 2013. "A Practical Approach for Extracting Tree Models in Forest Environments Based on Equirectangular Projections of Terrestrial Laser Scans." Remote Sensing, Vol. 5 (No. 11): pp. 5424-5448.

Fischler, M. A., and Bolles, R. C. 1981. "Random Sample Consensus: A Paradigm for Model Fitting with Applications to Image Analysis and Automated Cartography." Communications of the ACM, Vol. 24 (No. 6): pp. 381-395.

Gorte, B., and Pfeifer, N. 2004. "Structuring Laser-Scanned Trees Using 3d Mathematical Morphology." International Archives of Photogrammetry and Remote Sensing, Vol. 35 (No. B5): pp. 929-933.

Hackenberg, J., Wassenberg, M., Spiecker, H., and Sun, D. J. 2015. "Non Destructive Method for Biomass Prediction Combining TIs Derived Tree Volume and Wood Density." Forests, Vol. 6 (No. 4): pp. $1274-1300$. doi: $10.3390 / f 6041274$.

Hauglin, M., Astrup, R., Gobakken, T., and Næsset, E. 2013. "Estimating Single-Tree Branch Biomass of Norway Spruce with Terrestrial Laser Scanning Using Voxel-Based and Crown Dimension Features." Scandinavian Journal of Forest Research, Vol. 28 (No. 5): pp. 456-469.

Helmisaari, H.-S., Makkonen, K., Kellomäki, S., Valtonen, E., and Mälkönen, E. 2002. "Below-and above-Ground Biomass, Production and Nitrogen Use in Scots Pine Stands in Eastern Finland." Forest Ecology and Management, Vol. 165 (No. 1): pp. 317-326.

Huuskonen, S., Hakala, S., Mäkinen, H., Hynynen, J., and Varmola, M. 2014. "Factors Influencing the Branchiness of Young Scots Pine Trees." Forestry, Vol. 87 (No. 2): pp. 257-265. doi: 10.1093/forestry/cpt057.

Jaakkola, A., Hyyppä, J., Yu, X., Kukko, A., Kaartinen, H., Liang, X., Hyyppä, H., and Wang, Y. 2017. "Autonomous Collection of Forest Field Reference-the Outlook and a First Step with Uav Laser Scanning." Remote Sensing, Vol. 9 (No. 8): pp. 785.

Jenkins, J. C., Chojnacky, D. C., Heath, L. S., and Birdsey, R. A. 2003. "National-Scale Biomass Estimators for United States Tree Species." Forest Science, Vol. 49 (No. 1): pp. 12-35.

Jupp, D. L., and Lovell, J. L. 2007. Airborne and Ground-Based Lidar Systems for Forest Measurement: Background and Principles: CSIRO Marine and Atmospheric Research Canberra, ACT.

Kankare, V., Holopainen, M., Vastaranta, M., Puttonen, E., Yu, X., Hyyppä, J., Vaaja, M., Hyyppä, H., and Alho, P. 2013. "Individual Tree Biomass Estimation Using Terrestrial Laser Scanning." ISPRS Journal of Photogrammetry and Remote Sensing, Vol. 75 (No. 1): pp. 64-75. 
Kankare, V., Joensuu, M., Vauhkonen, J., Holopainen, M., Tanhuanpaa, T., Vastaranta, M., Hyyppa, J., Hyyppa, H., Alho, P., Rikala, J., and Sipi, M. 2014. "Estimation of the Timber Quality of Scots Pine with Terrestrial Laser Scanning." Forests, Vol. 5 (No. 8): pp. 1879-1895. doi: 10.3390/f5081879.

Kuprevicius, A., Auty, D., Achim, A., and Caspersen, J. P. 2013. "Quantifying the Influence of Live Crown Ratio on the Mechanical Properties of Clear Wood." Forestry, Vol. 86 (No. 3): pp. 361-369. doi: 10.1093/forestry/cpt006.

Lau, A., Bentley, L. P., Martius, C., Shenkin, A., Bartholomeus, H., Raumonen, P., Malhi, Y., Jackson, T., and Herold, M. 2018. "Quantifying Branch Architecture of Tropical Trees Using Terrestrial Lidar and 3d Modelling." Trees, Vol. (No.: pp. in press. doi: 10.1007/s00468-018-1704-1.

Liang, X., Kankare, V., Hyyppä, J., Wang, Y., Kukko, A., Haggrén, H., Yu, X., Kaartinen, H., Jaakkola, A., and Guan, F. 2016. "Terrestrial Laser Scanning in Forest Inventories." ISPRS Journal of Photogrammetry and Remote Sensing, Vol. 115 (No. 1): pp. 63-77. doi: 10.1016/j.isprsjprs.2016.01.006.

Liang, X. L., Litkey, P., Hyyppä, J., Kaartinen, H., Vastaranta, M., and Holopainen, M. 2012. "Automatic Stem Mapping Using Single-Scan Terrestrial Laser Scanning." IEEE Transactions on Geoscience and Remote Sensing, Vol. 50 (No. 2): pp. 661-670. doi: 10.1109/Tgrs.2011.2161613.

Liepiņš, J., Lazdiņš, A., and Liepiņš, K. 2018. "Equations for Estimating above- and Belowground Biomass of Norway Spruce, Scots Pine, Birch Spp. And European Aspen in Latvia." Scandinavian Journal of Forest Research, Vol. 33 (No. 1): pp. 58-70. doi: 10.1080/02827581.2017.1337923.

Lyhykäinen, H. T., Mäkinen, H., Mäkela, A., Pastila, S., Heikkila, A., and Usenius, A. 2009. "Predicting Lumber Grade and by-Product Yields for Scots Pine Trees." Forest Ecology and Management, Vol. 258 (No. 2): pp. 146-158. doi: 10.1016/j.foreco.2009.03.054.

Maguire, D. A., Johnston, S. R., and Cahill, J. 1999. "Predicting Branch Diameters on Second-Growth Douglas-Fir from Tree-Level Descriptors." Canadian Journal of Forest Research, Vol. 29 (No. 12): pp. $1829-1840$.

Mäkinen, H. 1999. "Effect of Stand Density on Radial Growth of Branches of Scots Pine in Southern and Central Finland." Canadian Journal of Forest Research, Vol. 29 (No. 8): pp. 1216-1224. doi: 10.1139/cjfr-29-8-1216.

Mäkinen, H., and Colin, F. 1998. "Predicting Branch Angle and Branch Diameter of Scots Pine from Usual Tree Measurements and Stand Structural Information." Canadian Journal of Forest Research, Vol. 28 (No. 11): pp. 1686-1696.

Newnham, G. J., Armston, J. D., Calders, K., Disney, M. I., Lovell, J. L., Schaaf, C. B., Strahler, A. H., and Danson, F. M. 2015. "Terrestrial Laser Scanning for Plot-Scale Forest Measurement." Current Forestry Reports, Vol. 1 (No. 4): pp. 239-251.

Ogaya, R., and Peñuelas, J. 2007. "Tree Growth, Mortality, and above-Ground Biomass Accumulation in a Holm Oak Forest under a Five-Year Experimental Field Drought." Plant Ecology, Vol. 189 (No. 2): pp. 291-299.

Osborne, N. L., and Maguire, D. A. 2015. "Modeling Knot Geometry from Branch Angles in DouglasFir (Pseudotsuga Menziesii)." Canadian Journal of Forest Research, Vol. 46 (No. 2): pp. 215224.

Penman, J., Gytarsky, M., Hiraishi, T., Krug, T., Kruger, D., Pipatti, R., Buendia, L., Miwa, K., Ngara, T., Tanabe, K., and Wagner, F. 2003. Good Practice Guidance for Land Use, Land-Use Change and Forestry. In IPCC National Greenhouse Gas Inventories Programme.

Pfeifer, N., Gorte, B., and Winterhalder, D. 2004. "Automatic Reconstruction of Single Trees from Terrestrial Laser Scanner Data." Proceedings of 20th ISPRS Congress.

Picard, N., Saint-André, L., and Henry, M. 2012. Manual for Building Tree Volume and Biomass Allometric Equations: From Field Measurement to Prediction: FAO; Food and Agricultural Organization of the United Nations. 
Pyörälä, J., Kankare, V., Vastaranta, M., Rikala, J., Holopainen, M., Sipi, M., Hyyppä, J., and Uusitalo, J. 2018a. "Comparison of Terrestrial Laser Scanning and X-Ray Scanning in Measuring Scots Pine (Pinus Sylvestris L.) Branch Structure." Scandinavian Journal of Forest Research, Vol. 33 (No. 3): pp. 291-298. doi: 10.1080/02827581.2017.1355409.

Pyörälä, J., Liang, X., Vastaranta, M., Saarinen, N., Kankare, V., Wang, Y., Holopainen, M., and Hyyppä, J. 2018b. "Quantitative Assessment of Scots Pine (Pinus Sylvestris L.) Whorl Structure in a Forest Environment Using Terrestrial Laser Scanning." IEEE Journal of Selected Topics in Applied Earth Observations and Remote Sensing, Vol. 11 (No. 10): pp. 3598-3607. doi: 10.1109/JSTARS.2018.2819598.

Raumonen, P., Kaasalainen, M., Akerblom, M., Kaasalainen, S., Kaartinen, H., Vastaranta, M., Holopainen, M., Disney, M., and Lewis, P. 2013. "Fast Automatic Precision Tree Models from Terrestrial Laser Scanner Data." Remote Sensing, Vol. 5 (No. 2): pp. 491-520. doi: $10.3390 /$ rs5020491.

Repola, J. 2009. "Biomass Equations for Scots Pine and Norway Spruce in Finland." Silva Fennica, Vol. 43 (No. 4): pp. 625-647.

Rubio-Cuadrado, Á., Bravo-Oviedo, A., Mutke, S., and Del Río, M. 2018. "Climate Effects on Growth Differ According to Height and Diameter Along the Stem in Pinus Pinaster Ait." iForestBiogeosciences and Forestry, Vol. 11 (No. 2): pp. 237-242. doi: 10.3832/ifor2318-011.

Samson, M. 1993. "Modelling of Knots in Logs." Wood Science and Technology, Vol. 27 (No. 6): pp. 429-437.

Samson, M. 2007. "Method for Assessing the Effect of Knots in the Conversion of Logs into Structural Lumber." Wood and Fiber Science, Vol. 25 (No. 3): pp. 298-304.

STMY. 2016. Grading Rules for Pine (Pinus Sylvestris) and Spruce (Picea Abies) Sawn Timber. In Nordic Timber - Grading rules 4th Edition. Umeå, Sweden.

Stovall, A. E. L., and Shugart, H. H. 2018. "Improved Biomass Calibration and Validation with Terrestrial Lidar: Implications for Future Lidar and Sar Missions." IEEE Journal of Selected Topics in Applied Earth Observations and Remote Sensing, Vol. 11 (No. 9): pp. in press. doi: 10.1109/JSTARS.2018.2803110.

Temesgen, H., Affleck, D., Poudel, K., Gray, A., and Sessions, J. 2015. "A Review of the Challenges and Opportunities in Estimating above Ground Forest Biomass Using Tree-Level Models." Scandinavian Journal of Forest Research, Vol. 30 (No. 4): pp. 326-335.

Temesgen, H., Shettles, M., and Hilker, T. 2016. "Examination of Uncertainty in Per Unit Area Estimates of Aboveground Biomass Using Terrestrial Lidar and Ground Data." Canadian Journal of Forest Research, Vol. 46 (No. 1): pp. 706-715. doi: 10.1139/cjfr-2015-0265.

Uusitalo, J. 1997. "Pre-Harvest Measurement of Pine Stands for Sawing Production Planning." Acta Forestalia Fennica, Vol. 259 (No. 1): pp. 1-56.

Vanninen, P., and Mäkelä, A. 2000. "Needle and Stem Wood Production in Scots Pine (Pinus Sylvestris) Trees of Different Age, Size and Competitive Status." Tree Physiol, Vol. 20 (No. 8): pp. 527-533.

Wallace, L., Lucieer, A., Watson, C., and Turner, D. 2012. "Development of a Uav-Lidar System with Application to Forest Inventory." Remote Sensing, Vol. 4 (No. 6): pp. 1519-1543.

Wilkes, P., Lau, A., Disney, M., Calders, K., Burt, A., de Tanago, J. G., Bartholomeus, H., Brede, B., and Herold, M. 2017. "Data Acquisition Considerations for Terrestrial Laser Scanning of Forest Plots." Remote Sensing of Environment, Vol. 196 (No. 1): pp. 140-153.

Xia, S., Wang, C., Pan, F., Xi, X., Zeng, H., and Liu, H. 2015. "Detecting Stems in Dense and Homogeneous Forest Using Single-Scan Tls." Forests, Vol. 6 (No. 11): pp. 3923-3945.

Zhong, L., Cheng, L., Xu, H., Wu, Y., Chen, Y., and Li, M. 2017. "Segmentation of Individual Trees from Tls and Mls Data." IEEE Journal of Selected Topics in Applied Earth Observations and Remote Sensing, Vol. 10 (No. 2): pp. 774-787.

Zianis, D., Muukkonen, P., Mäkipää, R., and Mencuccini, M. 2005. Biomass and Stem Volume Equations for Tree Species in Europe. 
Table 1. Stand information from a stand-wise forest inventory in 2013: Site location, site type (VT =

540 Sub-xeric heath forest i.e. Vaccinium type, MT = Mesic heath forest, i.e. Myrtillus type, OMT = Herb-

541 rich heath forest, i.e. Oxalis-Myrtillys type) and volume of pine ( $\left.V_{\text {Pine }}\right)$ and other species $\left(V_{\text {other }}\right)$ per

542 hectare. Scanning information: Mean 2D scanner-to-tree distance, the standard deviation $( \pm \mathrm{SD})$, and

543 mean registration error $( \pm \mathrm{SD})$.

\begin{tabular}{|c|c|c|c|c|c|c|c|c|}
\hline \multirow[t]{2}{*}{ Stand } & \multirow[t]{2}{*}{ Location } & \multirow[t]{2}{*}{ Site type } & \multirow[t]{2}{*}{$V_{\text {Pine }}\left(\mathrm{m}^{3 *} \mathrm{ha}^{-1}\right)$} & \multirow[t]{2}{*}{$V_{\text {other }}\left(\mathrm{m}^{3 *} \mathrm{ha}^{-1}\right)$} & \multicolumn{2}{|c|}{ Distance to the scanner (m) } & \multicolumn{2}{|c|}{ Registration error (mm) } \\
\hline & & & & & Mean & $\pm \mathrm{SD}$ & Mean & $\pm \mathrm{SD}$ \\
\hline 1 & Evo & VT & 220 & 10 & 8.9 & 4.18 & 1.2 & 3.5 \\
\hline 2 & Evo & VT & 250 & 20 & 10.85 & 4.81 & 1 & 2.2 \\
\hline 3 & Evo & OMT & 200 & 20 & 9.47 & 4.25 & 0.7 & 1.7 \\
\hline 4 & Evo & MT & 140 & 260 & 10.15 & 5.31 & 1.5 & 5.6 \\
\hline 5 & Orimattila & MT & 80 & 170 & 11.93 & 4.64 & 1.4 & 2.4 \\
\hline 6 & Orimattila & VT & 170 & 80 & 12.18 & 5.11 & 1.7 & 3.3 \\
\hline Mean & & & 176.7 & 93.3 & 9.79 & 4.83 & 1.3 & 5.6 \\
\hline
\end{tabular}

Table 2. Sample tree field measurement statistics. Mean and standard deviation $( \pm \mathrm{SD})$ values of diameter at breast height $(D B H)$, tree height $(H)$, the height of the lowest dead branch $\left(H_{d b}\right)$, and base

547 height of the live crown $\left(H_{l c}\right)$ of the sample trees.

\begin{tabular}{lrrrrrrrrr} 
& \multicolumn{3}{c}{$D B H(\mathrm{~cm})$} & \multicolumn{2}{c}{$H(\mathrm{~m})$} & \multicolumn{2}{c}{$H_{d b}(\mathrm{~m})$} & \multicolumn{2}{c}{$H_{l c}(\mathrm{~m})$} \\
Stand & Number of trees & Mean & \pm SD & Mean & \pm SD & Mean & \pm SD & Mean & \pm SD \\
1 & 30 & 28.9 & 3.4 & 22.6 & 1.2 & 4.8 & 2 & 14.4 & 1.7 \\
2 & 20 & 32.8 & 2.5 & 27 & 1.5 & 8.7 & 1.5 & 17.1 & 1.8 \\
3 & 30 & 28.6 & 4.2 & 22.9 & 1.8 & 4.4 & 2.3 & 13.9 & 1.9 \\
4 & 24 & 35.8 & 5.0 & 29 & 1.4 & 8.5 & 1.6 & 20.9 & 1.8 \\
5 & 28 & 34.7 & 4.2 & 27.7 & 1.8 & 10 & 2.9 & 18.8 & 1.6 \\
6 & 26 & 32.1 & 6.0 & 26 & 2.4 & 7.6 & 2.2 & 15.4 & 1.7 \\
All trees & 158 & 31.8 & 5.2 & 25.5 & 3 & 7 & 3.1 & 16.6 & 3.0
\end{tabular}

549 Table 3. Number of manually measured branches (N), minimum (Min), mean, maximum (Max), and 550 standard deviation ( $\left.{ }_{ \pm} \mathrm{SD}\right)$ of their height $\left(b_{h}\right)$, diameter $\left(b_{d}\right)$, and insertion angle $\left(b_{\alpha}\right)$ in different stem 551 sections. $\mathrm{H}_{\mathrm{db}}=$ Height of the lowest dead branch.

\begin{tabular}{llrrrrrrrrrrrrr} 
& $\mathrm{N}$ & \multicolumn{4}{c}{$b_{h}(\mathrm{~m})$} & \multicolumn{4}{c}{$b_{d}(\mathrm{~cm})$} & \multicolumn{4}{c}{$b_{\alpha}\left({ }^{\circ}\right)$} \\
& & & Min & Mean & Max & \pm SD & Min & Mean & Max & \pm SD & Min & Mean & Max & \pm SD \\
Below Hdb & 22 & 0.99 & 5.30 & 9.31 & 2.83 & 1.02 & 1.58 & 2.22 & 0.37 & 53.46 & 69.51 & 84.08 & 9.25 \\
Dead crown, lower half & 702 & 1.94 & 9.42 & 16.36 & 3.17 & 0.77 & 2.06 & 5.72 & 0.65 & 36.21 & 67.23 & 99.63 & 11.36 \\
Dead crown, upper half & 1075 & 7.66 & 13.33 & 20.51 & 2.71 & 0.78 & 2.25 & 5.56 & 0.66 & 30.87 & 64.37 & 98.39 & 11.66 \\
Live crown, lower half & 720 & 12.52 & 17.35 & 24.54 & 2.64 & 1.08 & 2.35 & 5.99 & 0.67 & 28.82 & 61.95 & 94.43 & 11.38 \\
Live crown, upper half & 42 & 15.85 & 19.92 & 25.61 & 2.72 & 1.39 & 2.44 & 4.71 & 0.78 & 20.80 & 63.37 & 78.95 & 13.60 \\
Total & 2561 & 0.99 & 13.43 & 25.61 & 4.24 & 0.77 & 2.21 & 5.99 & 0.67 & 20.80 & 64.75 & 99.63 & 11.67
\end{tabular}

553 Table 4. Results of the multiple regression analysis on the effect of scanner distance and occlusion 554 (Height above the live crown base $\left(H_{l c}\right)$ ) on the quantitative branch detection accuracy. $\mathrm{SE}=$ 555 parameter estimate standard error, $t=$ Student's t-test statistic of the parameter estimate, $p=$ 556 probability value of the t-test. Statistically significant parameter estimates $(p<0.05)$ are marked with an asterisk $(*)$. 


\begin{tabular}{ccccc}
$\begin{array}{c}\text { Quantitative branch detection } \\
\text { accuracy above } \boldsymbol{H}_{\boldsymbol{l c}}\end{array}$ & Estimate & SE & $t$ & $p$ \\
\hline Intercept & 1.564 & 0.165 & 9.494 & $<0.05^{*}$ \\
Distance from the scanner & -0.062 & 0.008 & -7.970 & $<0.05^{*}$ \\
Height above $H_{l c}$ & -0.003 & 0.016 & -0.170 & 0.87
\end{tabular}

558

559 Table 5. Results of the simple regression analysis on the effect of the sample-specific mean branch 560 diameter on the quantitative branch detection accuracy. $\mathrm{SE}=$ parameter estimate standard error, $t=$ 561 Student's t-test statistic of the parameter estimate, $p=$ probability value of the t-test. Statistically 562 significant parameter estimates $(p<0.05)$ are marked with an asterisk $(*)$.

\begin{tabular}{lrrrr} 
Quantitative branch detection accuracy & Estimate & SE & $t$ & $p$ \\
\hline Below Hdb & & & & \\
Intercept & -0.102 & 0.616 & -0.166 & 0.875 \\
Mean bd & 0.390 & 0.402 & 0.970 & 0.377 \\
Dead crown, lower half & & & & \\
Intercept & 0.401 & 0.097 & 4.131 & $<0.05^{*}$ \\
Mean bd & 0.110 & 0.044 & 2.493 & $<0.05^{*}$ \\
Dead crown, upper half & & & & \\
Intercept & 0.598 & 0.119 & 5.037 & $<0.05^{*}$ \\
Mean bd & 0.019 & 0.050 & 0.378 & 0.706 \\
Live crown, lower half & & & & \\
Intercept & 0.229 & 0.156 & 1.469 & 0.145 \\
Mean bd & 0.028 & 0.064 & 0.441 & 0.660 \\
Live crown, upper half & & & & \\
Intercept & -0.205 & 0.245 & -0.836 & 0.431 \\
Mean bd & 0.113 & 0.098 & 1.154 & 0.286 \\
Full tree & & & & \\
Intercept & 0.476 & 0.109 & 4.374 & $<0.05^{*}$ \\
Mean bd & 0.064 & 0.047 & 1.353 & 0.178
\end{tabular}




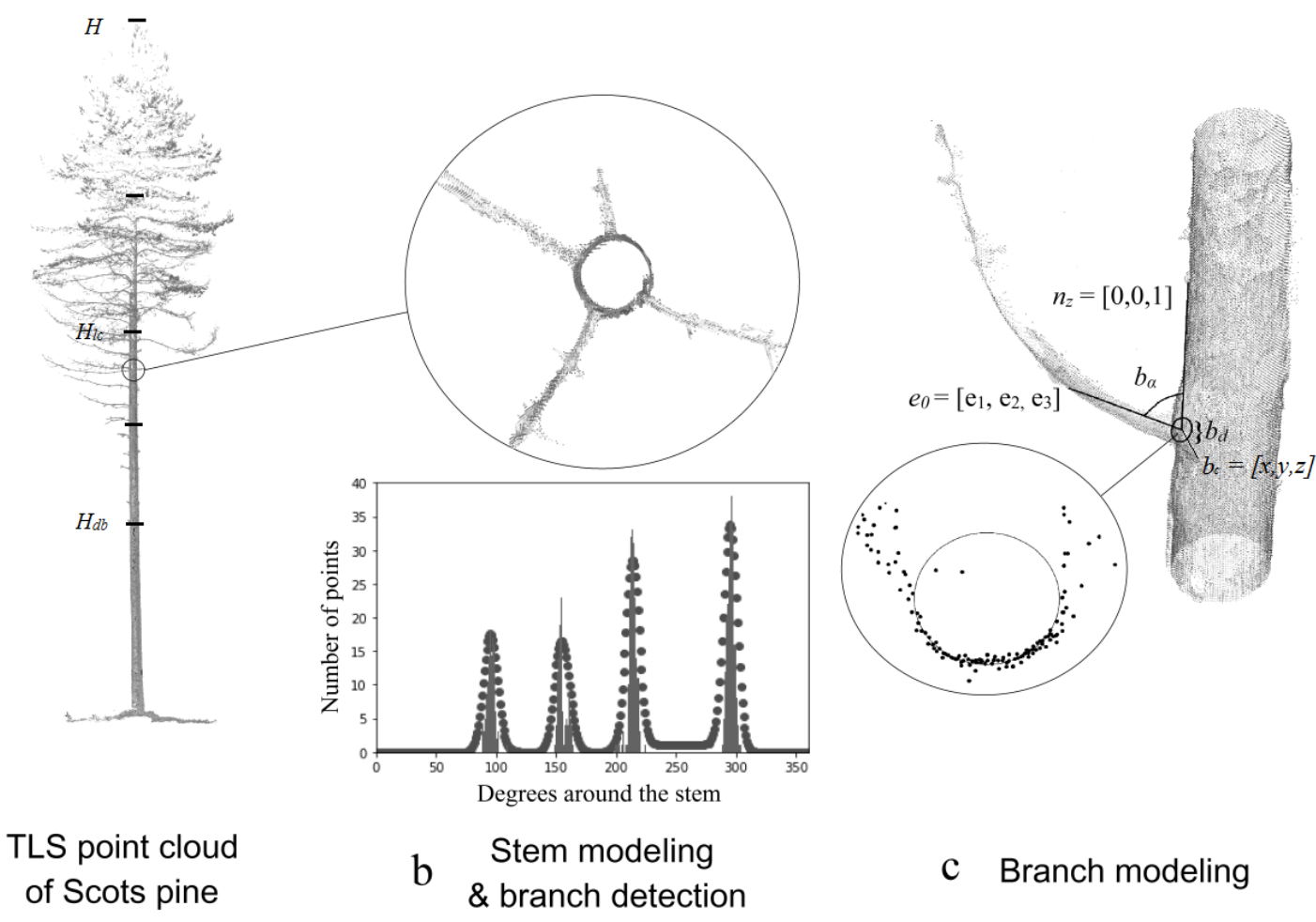

566 Figure 1. The sampling scheme and principle of the quantitative method applied for detecting and 567 modeling branches. a) $H_{d b}, H_{l c}$ and $H$ show the heights of the lowest dead branch, live crown base, 568 and tree top, respectively. Black lines show the limits between the sampled strata. b) The tree point 569 cloud was segmented vertically into slices of $15 \mathrm{~cm}$ thickness and $50 \mathrm{~cm}$ radius. For each segment, the 570 stem was modeled as a cylinder and the point distribution around the stem model was analyzed. 571 Locations that exhibit peaks in the point distribution were considered potential branch locations and 572 points from these locations were extracted for the modeling. c) The branch insertion angle $\left(b_{\alpha}\right)$ was 573 solved from the eigenvector $e_{0}$ of the branches and Z-axis $n_{z}$ using principal component analysis, and 574 the branch diameter $\left(b_{d}\right)$ and branch location $\left(b_{c}\right)$ were modeled by means of circle-fitting. 


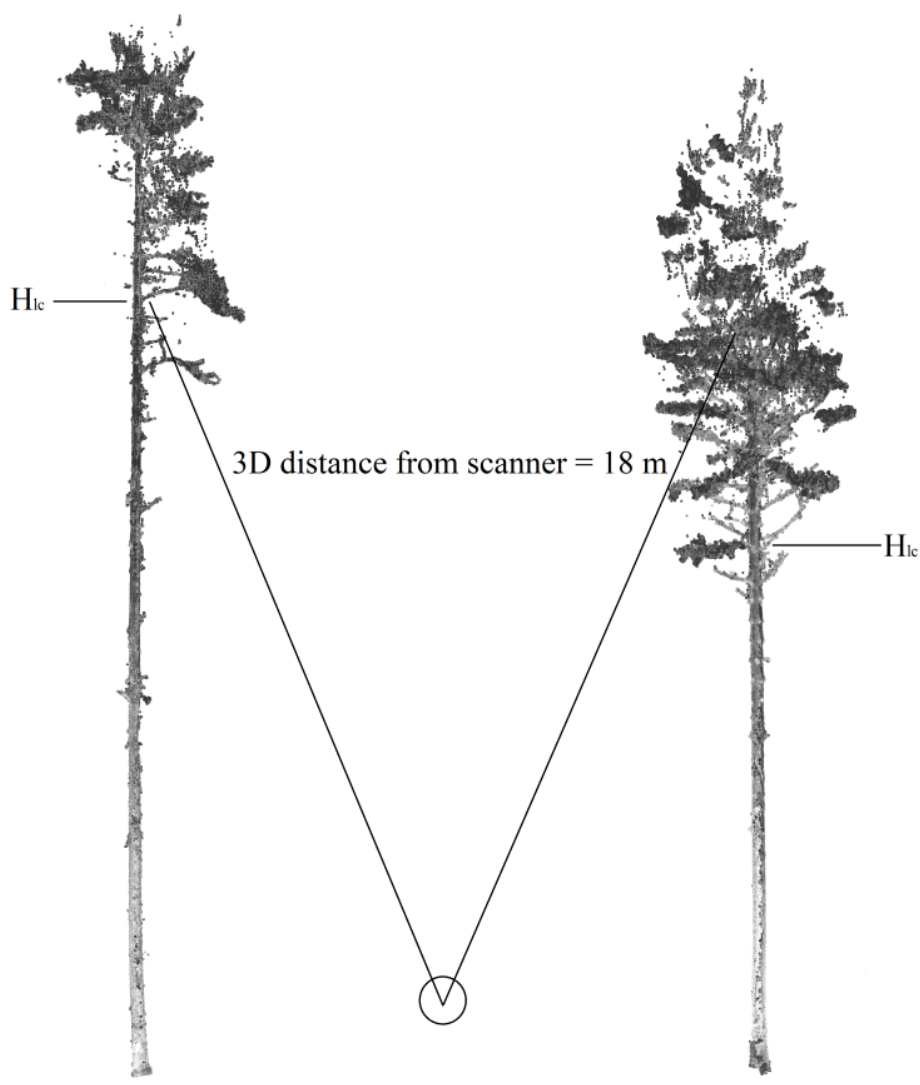

576 Figure 2. The simplified concept of the occlusion effect as indicated by the height above the base 577 height of the live crown $\left(H_{l c}\right)$. The figure illustrates two sample trees with different live crown base 578 heights. The scanner was situated at an equal distance from either tree. On the left-hand side, the line 579 shows the 3D distance from the scanner $(18 \mathrm{~m})$ to a branch $0 \mathrm{~m}$ above $H_{l c}$. On the right-hand side, the 580 line shows an equal 3D distance from the scanner to a branch approximately $6 \mathrm{~m}$ above $H_{l c}$. Due to 581 the unequal quantity of accumulated foliage between the scanner and each branch, the right-hand-side 582 branch is supposed less likely visible than the left-hand-side branch. Therefore, the height above $H_{l c}$ was considered to represent the magnitude of occlusion in this study. 


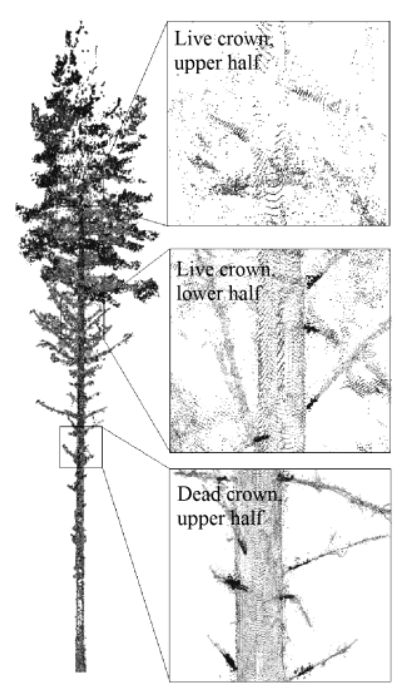

584

585

586

587

588

589

590

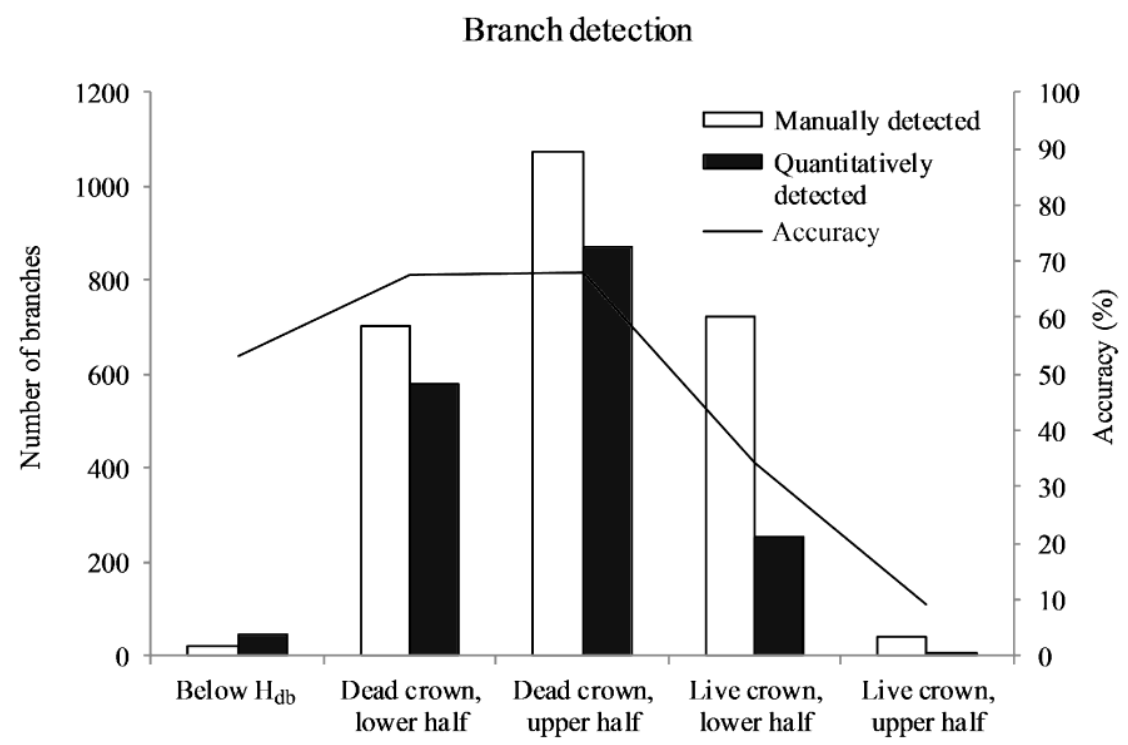

Figure 3. Branch detection performance in different stem sections. Left: illustrations of branch detection performance in the dead crown and lower and upper half of the live crown; branches detected quantitatively are highlighted in distinctive dark gray. Right: White and gray bars represent the number of branches detected manually and quantitatively, respectively. The line shows the accuracy (\%) of the quantitative method compared to the manual method. $H_{d b}$ is the height of the lowest dead branch measured in the field.
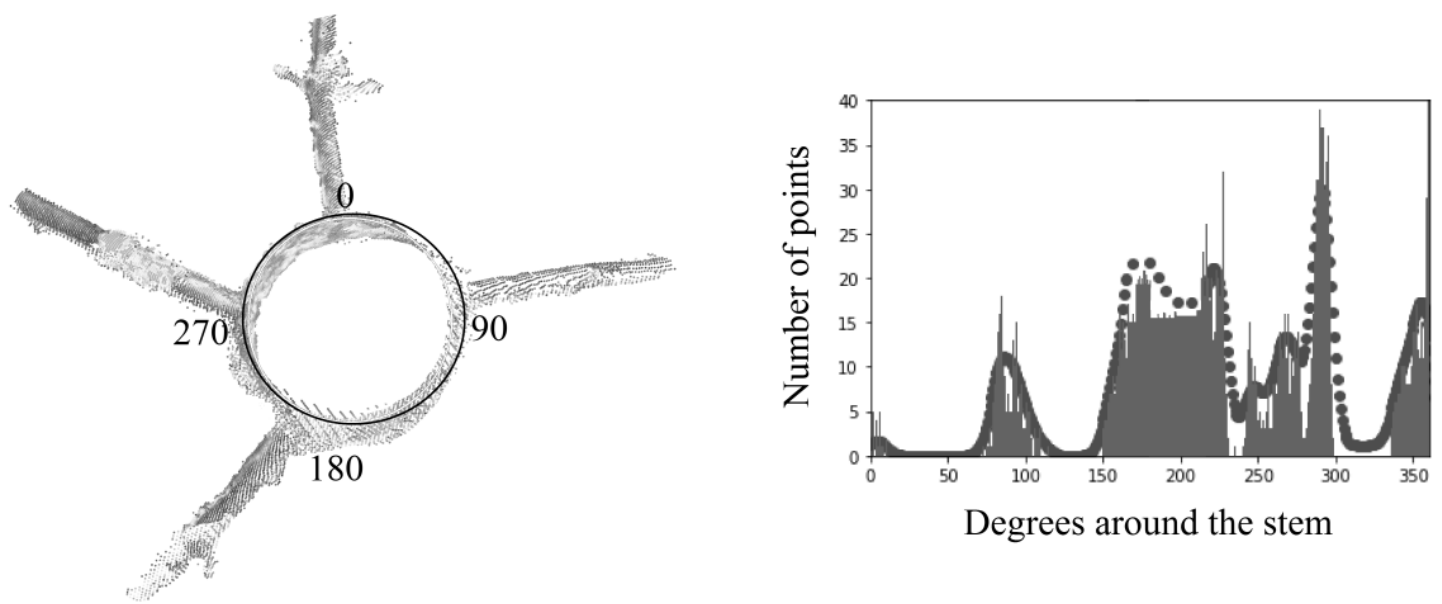

591

592 Figure 4. The effect of stem model to branch detection: forcing a cylindrical shape to the stem points excludes stem deformations, branch bumps, or other anomalies from the stem model. In our branch detection method, such occurrences distort the analyzed point densities around the stem model: in the illustrated whorl, the branch at approximately 220 degrees was omitted by the Continuous Wavelet Transform peak detection due to stem deformation between 150 and 270 degrees that distorts the baseline. 
598

599

600

601

602

603

604

605

606

607
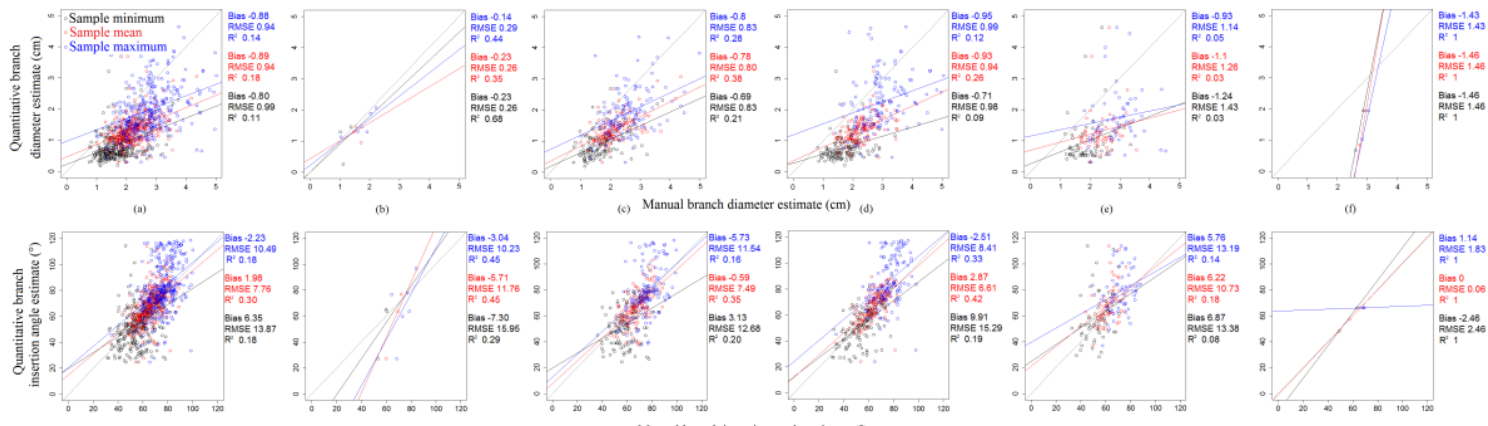

Figure 5. Comparisons between manually measured branch parameter references and quantitatively estimated branch parameters using samples from (a) all five strata in each tree, (b) below the lowest dead branch, (c) the lower half of the dead crown, (d) the upper half of the dead crown, (e) the lower half of the live crown, and (f) the upper half of the live crown. The upper row gives the results of the branch diameter comparisons between the data sets and the bottom row those of the branch insertion angle. Blue indicates the sample-specific maximum value of the branch parameter, red the mean, and black the minimum. The bias and root-mean-squared error (RMSE) give the error of the quantitative minimum, mean, and maximum estimates compared to the manual minimum, mean, and maximum observations. $\mathrm{R}^{2}$ indicates the regression model fit (solid line) between the two. 

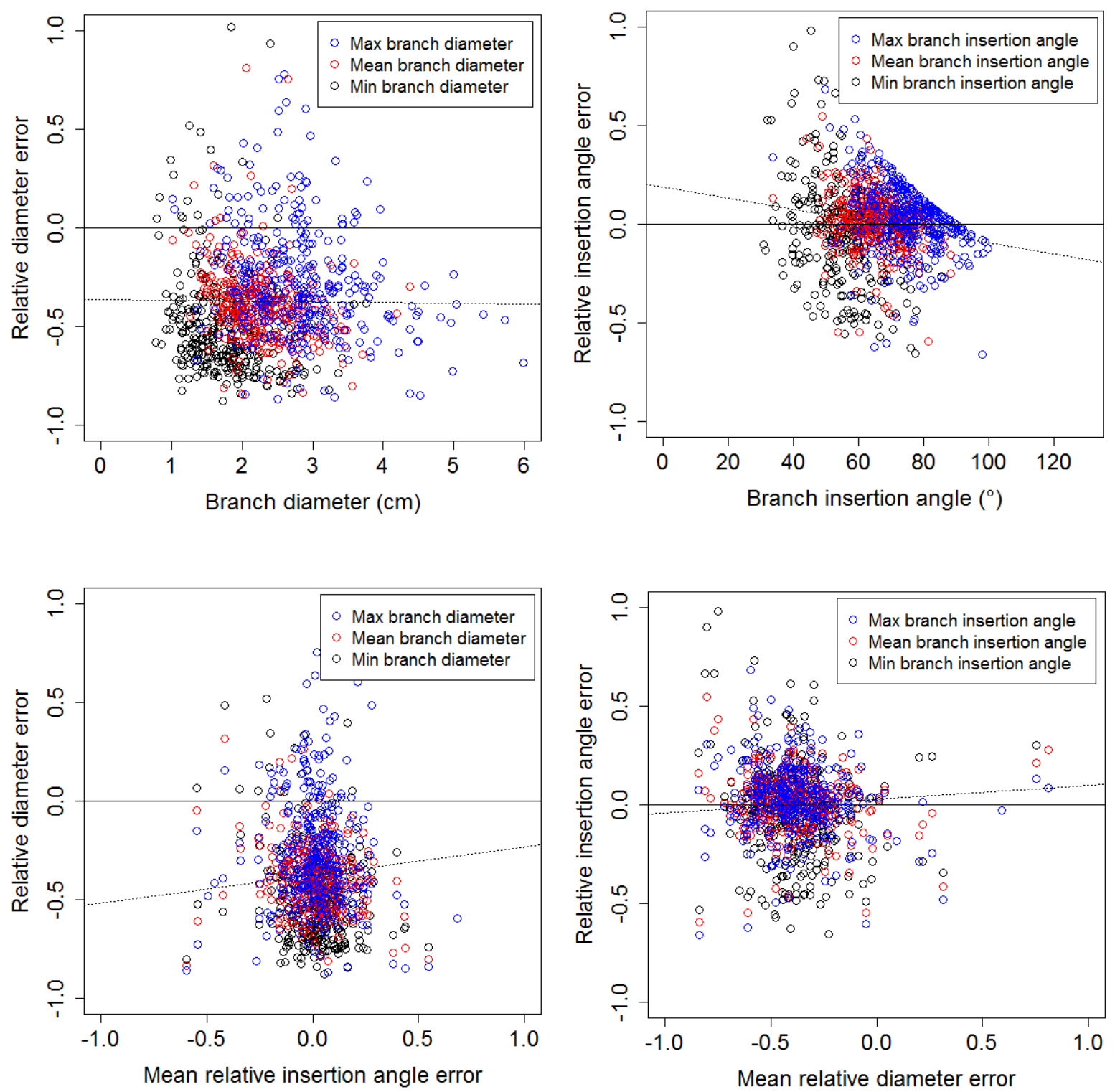

609 Figure 6. Sample-specific relative errors of $b_{d}$ and $b_{\alpha}$ in respect to the reference measurement value, 610 and the mean relative estimation error of the other branch parameter. Each observation refers to the 611 minimum (black), mean (red), or maximum (blue) values of the branch parameter in a sample (i.e., 612 branches along one 1-m stem section). A negative value on the y-axis refers to the quantitative model 613 underestimating the parameter, and vice versa. The dotted line shows the best linear fit between the 614 variables. 

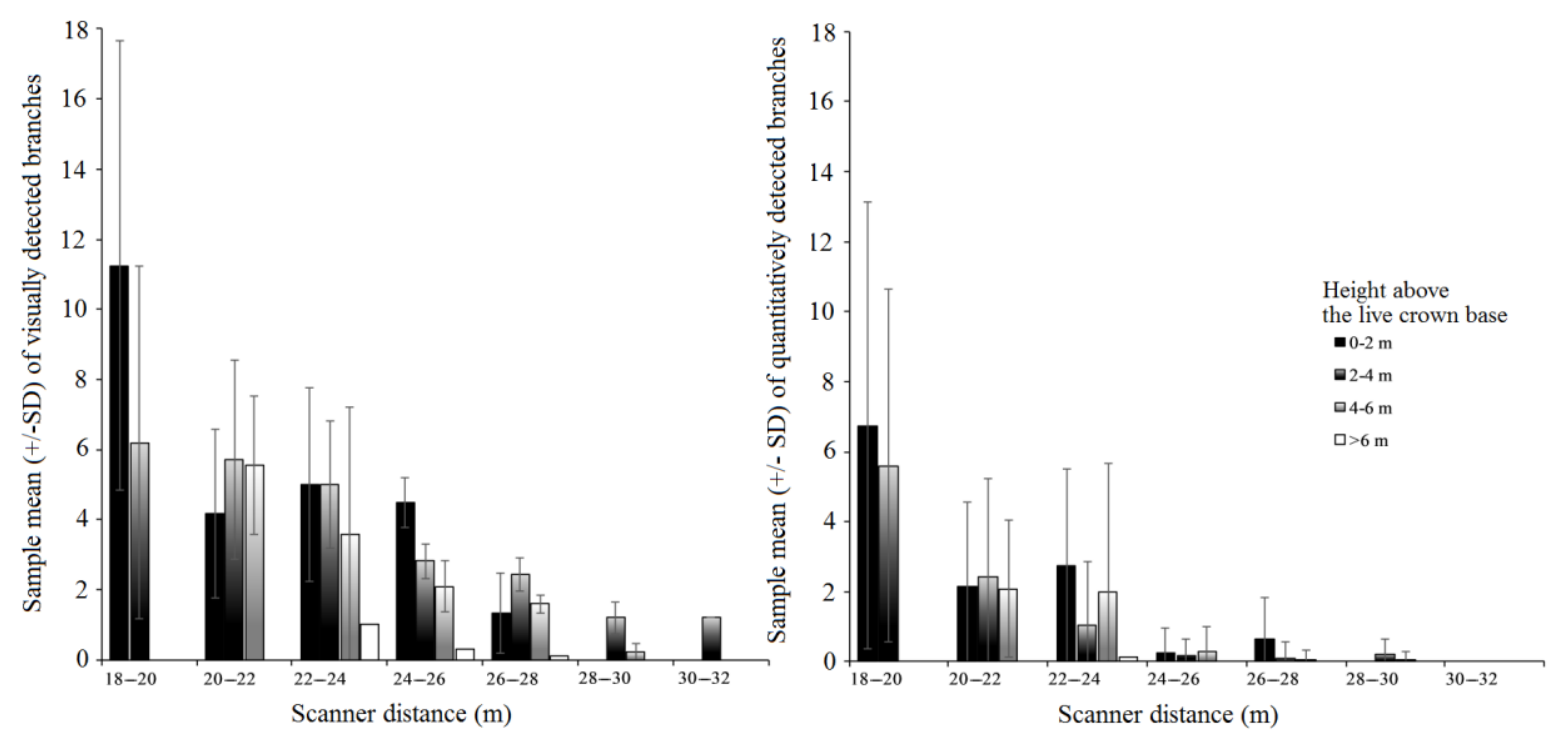

Figure 7. The effect of 3D distance from the scanner and the self-occlusion as indicated by the height 618 above the base height of the live crown $\left(H_{l c}\right)$, (color-coded bars) on the sample-specific mean number 619 ( \pm standard deviation) of manually detected branches (left), and quantitatively detected branches 620 (right). 